\title{
Adopción homoparental: Estudio de derecho comparado a partir de las perspectivas de los países latinoamericanos que la han aprobado
}

Homoparental adoption:

Study of comparative law from the perspectives of the latin american countries that have approved it.

Laura Juliana Chaparro Piedrahíta ${ }^{1 \otimes}$ Yudy Marcela Guzmán Muñoz

Fecha correspondencia:

Recibido: 4 de septiembre de 2017. Revisión: 17 de octubre de 2017. Aceptado: 1 de noviembre de 2017.

Forma de citar:

Chaparro, L.J., Guzmán, Y.M. (2017). Adopción homoparental: Estudio de derecho comparado a partir de las perspectivas de los países latinoamericanos que la han aprobado. Revista CES Derecho, (8), 2, 267-297.

Open access

Términos de uso

Licencia creative commons

Etica de publicaciones

Revisión por pares

Gestión por Open Journal System DOl: http://dx.doi.org/10.21615/ cesder.8.2.4

ISSN: 2145-7719

Sobre los autores:

1. Abogada Universidad EAFIT.

\section{Resumen}

El siguiente escrito presenta un estudio de derecho comparado sobre la adopción homoparental en los países latinoamericanos que han aprobado dicha institución (Argentina, los Estados Federales de Ciudad de México, Coahuila, Campeche, Colima, Michoacán y Morelos en México, Brasil, Uruguay y Colombia) con el propósito de identificar los cambios legislativos y jurisprudenciales derivados de su aprobación, y en el caso de Colombia observar el desarrollo que la jurisprudencia constitucional ha realizado hasta llegar a su reconocimiento, a través del fallo de la sentencia C-683 de 2015, permitiendo que en nuestro país las parejas del mismo sexo también puedan adoptar; lo anterior, supone un cambio relevante en la línea argumentativa que la Corte Constitucional había elaborado hasta entonces, aunque mantiene abiertas las discusiones que giran en torno a esta temática.

Se reseñan brevemente también algunos casos como Atala Riffo y Niñas vs. Chile desatado en la Corte Interamericana de Derechos Humanos y las reflexiones que este aporta al debate sobre adopción homoparental en la región.

Este trabajo pretende resaltar todas aquellas razones jurídicas que han sido objeto de discusión en los países latinoamericanos que han aprobado la homoparentalidad como un ejercicio académico que permita comprender mejor los alcances de este derecho en nuestro continente.

Palabras clave: Homoparentalidad, población LGBTI, derecho comparado, jurisprudencia constitucional.

\section{Abstract}

The following article presents a study of comparative law on homoparental adoption in the Latin American countries that have approved this institution (Argentina, the Federal States of Mexico City, Coahuila, Campeche, Colima, Michoacán and Morelos in Mexico, Brazil, Uruguay and Colombia), 
with the purpose of identifying the legislative and jurisprudential changes derived from its approval, and in the case of Colombia, observe the development that the constitutional jurisprudence has made up to its recognition, through the court ruling number C-683 of 2015, allowing same-sex couples in our country to adopt. This is a relevant change in the argumentative line that the Constitutional Court had developed until then, although it keeps open the discussions that revolve around this issue.

Some cases like Atala Riffo and Girls vs. Chile unleashed in the Inter-American Court of Human Rights and the reflections that it contributes to the debate on homoparental adoption in the continent.

This work aims to highlight all those legal reasons that have been the subject of discussion in Latin American countries that have approved homoparentality as an academic exercise that allows us to better understand the scope of this right in our continent.

\section{Introducción}

La homoparentalidad ${ }^{1}$ es una novedad histórica ligada a dos fundamentales transformaciones en la cultura occidental: por un lado, el hecho que desde el siglo XXI los niños son formados con nuevos valores como consecuencia de los actuales conceptos de familia que han surgido y, por otro, que dentro del dominio científico desde hace más o menos quince años la homosexualidad ya no es considerada por la medicina como una patología ni por la psicología como una perversión. ${ }^{2}$ Si la adopción homoparental genera tantos interrogantes, es porque redefine el tradicional triángulo padre-madre-niño que ha constituido, hasta ahora, el modelo familiar tradicional. Además, si el tema se está abriendo debate en la contemporaneidad es porque nos invita a reflexionar sobre nuevas concepciones acerca de la filiación, e indiscutiblemente sobre el concepto de familia.

La adopción por parte de parejas del mismo sexo constituye un cambio del paradigma referente a la posibilidad que los menores puedan hacer parte de una familia y un hogar, incluso si este está conformado por personas de igual sexo. Si bien la homosexualidad tiene como castigo la pena de muerte o prisión en setenta y cinco países entre ellos Emiratos Árabes Unidos, Arabia Saudita, Yemen, Sudán, Irán y Mauritania, la homoparentalidad se ha consagrado paulatinamente en los ordenamientos jurídicos de diversos países del mundo como una figura jurídica que vela por los derechos de todos los menores a tener una familia para desarrollarse en forma integral. Muchas instituciones, entre ellas la Federación Española de Sociedades de Sexología, coinciden al afirmar que la homosexualidad en sí misma no puede ser argumento suficiente para negar la adopción a las parejas del mismo sexo, toda vez que diversas investigaciones antropológicas realizadas a través de las culturas y los tiempos que versan sobre familias, hogares y las relaciones que de ellas surgen, no proporcionan apoyo alguno a la idea de que la civilización o un orden social viable dependen de la familia como una institución únicamente heterosexual. (Federación Española de Sociedades de Sexología, 2005).

\footnotetext{
1. El término homoparentalidad, es un neologismo creado en Francia en 1977 para designar todas las situaciones familiares en las que al menos un adulto que se autoidentifica como homosexual es, a su vez, el padre de al menos un niño.

Este concepto hace referencia a aquellas familias que están conformadas por personas del mismo sexo. Se refiere tanto a las parejas gay y lesbianas que, como pareja, acceden a la maternidad o paternidad, ya sea a través de la institución de la adopción o la maternidad subrogada, como a las familias constituidas por una pareja gay o lesbiana que educa y vive con los hijos de alguno de sus miembros, producto de una relación heterosexual previa.

2. La homosexualidad fue eliminada del Manual de Estadística y Diagnóstico de los Trastornos Mentales de la Asociación Americana de Psiquiatría en su tercera emisión de 1973. Posteriormente. El 17 de mayo de 1990 la Organización Mundial de la salud excluyó la homosexualidad de la Clasificación Estadística Internacional de Enfermedades y otros Problemas de Salud. La decisión, se basó, en parte en los pronunciamientos de la American Psychological Association, organización que luego de diversas investigaciones, concluyó que no existe ninguna asociación inherente entre las orientaciones sexuales y la psicopatología, señalando entonces que las orientaciones lesbianas, gay y bisexuales no son trastornos, pues tanto la conducta heterosexual como la homosexual son aspectos normales de la sexualidad humana.
} 
En Latinoamérica, son cinco los países que han aprobado esta Institución: Argentina en el año 2010, Brasil en 2010, Uruguay en el año 2013 (aunque aprobado anteriormente en un texto legal ambiguo en 2009), los Estados Federales de Ciudad de México, Coahuila, Michoacan, Campeche, Colima, y Morelos en 2010, 2014 y 2016 respectivamente y Colombia en 2015 en una sentencia emitida por la Corte Constitucional; ello supone un cambio en las tradiciones históricas de dichos países, ya que precisamente algunas de estas son las que excluyen o niegan derechos.

Los países de América Latina comparten una misma tradición socio-cultural; de acuerdo con el Banco de Desarrollo de América Latina, la síntesis cultural de la región ha permeado todas sus épocas y simultáneamente cubre todas sus direcciones, a saber: trabajo y producción, asentamientos humanos y estilo de vida, lenguaje y expresión artística, organización política y vida cotidiana. Y, precisamente en su rol de reserva de identidad cultural, América Latina, tal vez más que ninguna otra región, ha ido desarrollando un modelo de semejanza en su intento por subordinar las culturas particulares a los dictados de la razón instrumental (Radi, 2000). Por ello, los países latinoamericanos comparten también, como característica común, las diversas formas de discriminación social a la población LGBTI, que se encuentran aún presentes en la concepción cultural de un grupo mayoritario. Por esta razón, en el ejercicio y administración de los nuevos derechos que va alcanzando la población LGBTI se configuran nuevos desafíos en nuestro continente.

Con todo, los cambios legislativos y jurisprudenciales introducidos en cada uno de los países que han reconocido la adopción homoparental han estado sujetos a diferentes contextos y argumentos. De ello se deriva la necesidad de realizar un estudio de derecho comparado a través de un método macro-comparatista ${ }^{3}$ que permita centrar nuestra atención en las similitudes y las diferencias entre los sistemas objeto de nuestra comparación sin dejar de lado la posibilidad de su equivalencia funcional, ya que como lo indica el jurista italiano Alessandro Pizzorusso:

la existencia de una pluralidad de ordenamientos recíprocamente independientes constituye el presupuesto de cualquier indagación de tipo comparativista, las relaciones entre los ordenamientos jurídicos que actúan en diferentes niveles sobre un mismo territorio y respecto de las mismas personas es de particular importancia para la comparación de las normas sobre la producción jurídica que caracteriza a los diferentes ordenamientos jurídicos. (Pizzorusso, 1987).

En Colombia, tradicionalmente los movimientos sociales y minorías han recurrido a los principios constitucionales para interpelar causas y modificar prácticas que han sido históricamente reprimidas y reprobadas. Desde un punto de vista institucional, esta tradición se explica por el alto grado de apertura del que goza nuestro sistema constitucional consagrado, entre otras, en las acciones públicas de inconstitucionalidad y en el derecho fundamental de intervenir para defender o atacar la norma analizada dentro de este marco de control de constitucionalidad 4 . Con todo, la jurisprudencia que la Corte Constitucional ha creado para responder a estas demandas ciudadanas ha generado efectos contradictorios en términos de democracia.

3. Toda vez que se aborda el estudio de los sistemas jurídicos desde la globalidad, esto es, desde la comparación entre dos o más sistemas jurídicos para ver sus genéricas analogías y diferencias, sus métodos de análisis e investigación, y los procedimientos empleados para ello

4. De acuerdo con el artículo 242 numeral $1^{\text {a }}$ de la Constitución Política de 1991, “cualquier ciudadano podrá ejercer las acciones públicas previstas en el artículo precedente, e intervenir como impugnador o defensor de las normas sometidas a control en los procesos promovidos por otros, así como en aquellos para los cuales no existe acción pública". Ello significa que los ciudadanos pueden no solo instaurar acciones públicas de inconstitucionalidad sino que además pueden intervenir para defender o criticar la ley en todos aquellos procesos en los cuales la Corte Constitucional analiza la conformidad de una norma a la Constitución. 
Es evidente que diversas autoridades, entre ellas la Procuraduría General de la Nación representada durante varios años por el ahora ex Procurador General Alejandro Ordóñez utilizó los recursos de esta institución para evitar la protección y reconocimiento de los derechos de las personas homosexuales, aludiendo a criterios morales y religiosos, muy a pesar de que, es su propia función defender los derechos fundamentales de los ciudadanos. En ese sentido, ¿qué podría esperarse de un país en el que, el derecho tiene poca operatividad en la realidad social, pues muchas de sus normas se convierten en un ideal utópico al ser ignoradas por los órganos ejecutores, quienes en su lugar hacen uso de su discrecionalidad y concepciones personales como estándares de aplicación del derecho?

Así, el presente escrito surge como resultado del estudio de las leyes y jurisprudencia sobre la adopción homoparental en una muestra de cinco países. Se analizaron no solo las leyes aprobatorias de cada uno de ellos sino también los Códigos Civiles, jurisprudencia y casos relevantes. De estas fuentes, se examinaron los siguientes temas: 1. definición de la figura, 2. cambios legislativos representativos, 3. requisitos para adoptar, 4. reformulación del concepto de familia.

Se hizo también un breve recorrido por la jurisprudencia constitucional referida a la adopción homoparental en Colombia, a través de los argumentos que la Corte Constitucional ha introducido en sus fallos para justificar el paulatino reconocimiento a un grupo social cuyos derechos no habían sido reconocidos en su totalidad hasta hace muy poco tiempo.

Nuestra investigación supuso un trabajo documental centrado en el análisis de fuentes primarias y secundarias. La estrategia de tipo documental está basada en primera instancia en la búsqueda de leyes y jurisprudencia de cada de uno de los países objeto de estudio; además, el estudio de la doctrina fue importante, pues permitió, como medio auxiliar, una mejor comprensión de las reglas de derecho presentes en los ordenamientos jurídicos estos países.

Para dar cumplimiento a los objetivos de este trabajo, el estudio se encuentra dividido en tres partes fundamentales. En la primera parte, expondremos los cambios legislativos introducidos en los ordenamientos jurídicos de los países latinoamericanos que han aprobado la homoparentalidad, además de referenciar algunos casos relevantes. La segunda parte, reseña un breve recorrido por la jurisprudencia constitucional sobre la adopción por parte de parejas homosexuales en Colombia, especialmente la sentencia C-683 de 2015 que ha dado vía libre a esta institución jurídica. Por último, finalizamos con una reflexión en la que expondremos las razones que nos llevan a concluir que, basados en los argumentos introducidos por cada uno de los países analizados, si bien existen semejanzas y argumentos comunes en cuanto a los principios constitucionales protegidos frente a los argumentos expuestos por la Corte Constitucional colombiana sus decisiones aún no otorgan la suficiente protección tanto a las parejas homosexuales como a los niños a la hora de adoptar y ser adoptados.

No es entonces objeto del presente artículo analizar la relación causal entre las demandas sociales referidas a los derechos de las personas homosexuales y la reacción de las instituciones en el continente latinoamericano frente a estas, ni mucho menos establecer las circunstancias histórico-coyunturales requeridas para determinar cuándo el derecho es efectivo y generar así algún tipo de cambio social, toda vez que este estudio pretende, desde una perspectiva estrictamente jurídica, discutir 
el diseño constitucional de las legislaciones, analizar las decisiones judiciales que versan sobre la homoparentalidad y reflexionar acerca de la idoneidad sustantiva de dichas decisiones.

\section{Adopción por parte de parejas del mismo sexo en América Latina: cambios legislativos y fallos relevantes}

La homoparentalidad comenzó a ser aprobada en diferentes Estados del mundo a partir del año 2002, inicialmente en Suecia y Sudáfrica; posteriormente en España en 2005, Islandia y Bélgica en el año 2006 y Noruega en 2009. En nuestro continente, la adopción de parejas del mismo sexo en el marco de las legislaciones que nada decían al respecto se había presentado a través de casos de adopción unipersonal integrativa del hijo biológico adoptivo de una persona cuya pareja del mismo sexo pretendía tener un vínculo filial a través de esta institución; esta forma de adopción aún sigue siendo legal en países como Costa Rica y Chile. ${ }^{5}$

Sin embargo, al año 2016, Argentina, los Estados Federales de Ciudad de México, Coahuila, Michoacan, Campeche, Colima, y Morelos, en México y Uruguay aprobaron la institución de la adopción entre parejas del mismo sexo; tal decisión surgió como consecuencia de la aprobación de una ley de matrimonio igualitario, lo que generó una serie de modificaciones en sus códigos civiles, permitiendo así que las parejas homosexuales puedan adoptar. Por otro lado, Brasil no cuenta con una ley de matrimonio igualitario que haga extensivos a las parejas homosexuales los derechos personales derivados de un matrimonio, entre ellos la posibilidad de adoptar, ni mucho menos una ley que apruebe la figura de la adopción homoparental; en este país las decisiones se han hecho a través de la vía judicial, pues el Supremo Tribunal Federal ha resuelto varios casos en los que ha sentado un importante precedente, al permitir que personas homosexuales puedan adoptar menores conjuntamente.

Es imposible no aludir a ciertos avances legislativos y jurisprudenciales en estos países, máxime porque hasta hace algún tiempo carecían de regulación integral sobre el matrimonio, las uniones convencionales del mismo sexo y de manera evidente la adopción. Precisamente en dichos Estados la doctrina y la jurisprudencia habían estado ocupando un lugar privilegiado para plantear y abordar dicha cuestión.

Como se indicó anteriormente, en la primera parte de este trabajo, presentamos un estudio de derecho comparado sobre la institución jurídica de la adopción homoparental en cada uno de estos cuatro países, así:

México: La igualdad e interés superior del menor son principios que se adecúan a un nuevo modelo de familia.

En este país, desde el año 2009 comenzó un debate acerca del verdadero concepto de familia. El 21 de diciembre de 2009, el Pleno de la Asamblea Legislativa del Distrito Federal, aprobó la reforma del Código Civil y el Código de Procedimientos Civiles permitiendo el matrimonio entre personas del mismo sexo, pues este derecho no puede ser restringido como resultado de la orientación sexual. Esta reforma eliminó el concepto hombre y mujer como base del matrimonio. Además, como consecuencia de la aprobación de esta figura, se aprobó también una modificación al artículo 391 para eliminar la imposibilidad de adoptar a los cónyuges o concubinos del mismo sexo.

5. En ambos países, la legislación y los protocolos vigentes sólo contemplan la adopción por parte de parejas heterosexuales, si bien los homosexuales pueden adoptar de forma individual. 
El nuevo artículo indica que:

Los cónyuges o concubinos podrán adoptar, cuando los dos estén conformes en considerar al adoptado como hijo y aunque sólo uno de ellos cumpla el requisito de la edad (...) pero siempre y cuando la diferencia de edad entre cualquiera de los adoptantes y el adoptado sea de diecisiete años cuando menos.

En aquella ocasión, los ministros resolvieron que es constitucional el derecho de adoptar niños para los matrimonios entre personas del mismo sexo aduciendo al principio de igualdad que debe predicarse de ambas parejas y al interés superior del menor, toda vez que en este país muchos niños viven en casas hogares sin tener el afecto y cuidado de una familia.

Desde ese momento, La Suprema Corte de Justicia de la Nación reconoció la existencia de diversos tipos de familia. Especial mérito a este reconocimiento, se encuentra en la Acción de Inconstitucionalidad 2/2010, donde esta corporación argumentó que no existe un único tipo de familia, como se había conocido tradicionalmente, debido a que existen diversos tipos cuya finalidad principal no significa necesariamente la procreación, incluso en matrimonios heterosexuales. En este sentido, el artículo 143 del Código Civil mexicano no era idóneo para cumplir con la finalidad de la protección de la familia como realidad social, debido a que la norma impugnada "Pretende vincular los requisitos en cuanto a las preferencias sexuales de quienes pueden acceder a la institución matrimonial de procreación".

La Suprema Corte Mexicana, al decidir sobre esta Acción de Inconstitucionalidad promovida por el Procurador General, con el fin de solicitar la nulidad de las normas señaladas indicó que:

La existencia de matrimonios y familias con miembros homosexuales, ni impulsa ni prohíbe, ni mucho menos excluye la continuación y crecimiento de las familias heterosexuales. No se trata de destruir a la familia, sino de enriquecer su contenido, de reconocer su variedad, de hacer posible la unión de personas para cuidarse, quererse, protegerse y tener vida en común. (Acción de Inconstitucionalidad 2/2010, 2010)

Sin embargo, aclara la Corte, no puede desconocerse que toda persona independientemente de su orientación sexual debe cumplir con el lleno de requisitos que impone la ley para poder adoptar; no se trata solamente de dar un hogar al menor, sino de proporcionarle una familia que pueda cumplir con un mínimo de condiciones que aseguren, en la medida de lo posible, el óptimo desarrollo del niño.

La adopción también fue aprobada en el Estado de Coahuila de Zaragoza. Siguiendo la fundamentación de la Suprema Corte de Justicia de la Nación en el amparo en revisión 581/2012, negar el derecho a parejas del mismo sexo a contraer matrimonio y por consiguiente adoptar, con el argumento de que existen otras figuras como el pacto civil de solidaridad, podía constituir una medida discriminatoria, pues,

los modelos para el reconocimiento de las parejas del mismo sexo, sin importar que su única diferencia con el matrimonio sea la denominación que se da a ambos tipos de instituciones, son inherentemente discriminatorios porque constituyen un régimen de "separados pero iguales. La exclusión de éstos de la institución matrimonial perpetúa la noción de que las parejas del mismo sexo 
son menos merecedoras de reconocimiento que las heterosexuales, ofendiendo con ello su dignidad como personas" (Amparo en revisión 581/2012, 2012). Por ello, en febrero del año 2014 el Legislativo Estatal modificó el Código Civil para permitir también la adopción a las parejas homosexuales.

El primer y más mencionado caso de adopción por parte de una pareja homosexual en México se presentó el de 2011, cuando una pareja de lesbianas solicitó la adopción de un menor en la Ciudad de México luego de que en el año 2010 la Suprema Corte de Justicia de la Nación ratificara el derecho a la adopción homoparental. Una vez cumplidos todos los requisitos, el Sistema para el Desarrollo Integral de la Familia (DIF) autorizó su adopción.

En el año 2016, la adopción fue aprobada en cuatro Estados adicionales: Campeche, Colima, Michoacán y Morelos. En el caso de Colima, el Decreto 103 del de junio de 2016, a través del cual se reconoció la figura, argumentó esta decisión en su exposición de motivos, así:

El Estado de Colima, hoy en día se une a esta lucha de protección y fortalecimiento de derechos para aquellos grupos más vulnerados, de la cual la comunidad LGBTTTI forma parte, siendo personas con los mismos derechos y obligaciones que cualquier heterosexual, debiendo proporcionárseles las mismas oportunidades sin señalamientos, ni exclusión de derechos. Siendo las normas no un privilegio de unos cuantos, sino de toda una sociedad por igual, el matrimonio como figura conyugal debe ser considerada una unión entre dos personas sin importar su género, sin excluirlos de esos derechos y obligaciones que esta figura ostenta, ya que a esta comunidad, cuando se le reconocía un enlace conyugal no se valoraban los mismos derechos y existía una notable diferenciación normativa con aquellas parejas a las que si se les reconocía una unión matrimonial. (Congreso Constitucional del Estado de Colima, 2016).

En el Estado de Campeche la aprobación de la adopción homoparental, fue el resultado del pronunciamiento hecho en la Acción de Inconstitucionalidad 8/2014, argumentando que:

Lo que debe garantizar el legislador es que, en el procedimiento para autorizar la adopción de un menor (...) en aras de lograr el pleno respeto a los derechos de la niñez, se garantice que ésa sea su mejor opción de vida (...), al margen de la orientación sexual de la mujer o del hombre solteros solicitantes, o de si se trata de un matrimonio heterosexual o de parejas del mismo sexo, pues, se reitera, este último aspecto no puede ser, en forma alguna, el que decida si la adopción procede o no, al no afectar la capacidad de una persona para prodigar a un menor el cuidado y amor debidos. (Comisión de de Derechos Humanos del Estado de Campeche, 2014).

Argentina: el paulatino cambio en el concepto tradicional de familia y el derecho de los homosexuales a conformarla.

En la República Argentina, como en el resto del mundo occidental, el devenir de los tiempos ha ido modificando, de modo efectivo, el concepto de familia. Con anterioridad a la Ley 26.618 por la cual se aprobó el matrimonio entre personas del mismo sexo en este país, existían dos tipos de adopción: aquella de carácter unipersonal, 
consagrada en el artículo 312 del Código Civil, que establecía que nadie podía ser adoptado por más de una persona simultáneamente, excepto si los adoptantes eran cónyuges y la adopción que se realizaba del hijo del cónyuge del adoptante en el artículo 311 , inciso $1^{\circ}$. Nada se decía sobre la posibilidad de adoptar al hijo del compañero homosexual, por lo que se presentaron diversos casos en los que se solicitó la adopción simple del hijo o de la hija del concubino/a; durante un largo período de tiempo estas peticiones fueron negadas, aunque posteriormente los jueces adoptaron una postura más liberal, permitiendo así la adopción de estos menores.

Sin embargo, las reflexiones tendientes a plantear la obligación de adaptar el concepto de familia a los factores reales de poder de la época datan de mucho antes. Un ejemplo de ello es el fallo del 20 de octubre 1998 del Juzgado Civil, Comercial y Minas $N^{\circ} 10$ de Mendoza, basado en un caso en el que un hombre solicitaba que se certificara su convivencia como concubino con su pareja del mismo sexo para incluirlo como beneficiario en la categoría de grupo familiar ante el Instituto de Obra Social del Ministerio de Economía de la Nación.

En aquella ocasión, se planteó por primera vez la necesidad de reformular el concepto de familia que existía hasta entonces en el país. Al respecto, la corporación indicó que:

Esta manera de entender la familia es una muestra del cambio que se viene produciendo en la imagen que tradicionalmente nos hemos hecho de los padres. La declaración de Derechos humanos define la familia sin precisar su contenido (...) El avenimiento de las familias adoptivas, ensambladas, mixtas, los padres solteros por elección y las parejas homosexuales, obligan a revisar las posturas conservadoras. La configuración de una noción de familia resulta central al momento preciso de conceder la adopción; tengamos en cuenta que la estabilidad familiar, es, precisamente, un elemento fundamental para que, en el caso concreto de una adopción, esta sea aprobada. De ahí, como veremos, la importancia que adquiere la institución del matrimonio ya que garantiza en mayor medida la preservación del núcleo familiar del adoptado. (Juzgado Civil, Comercial y Minas Nª10 de Mendoza, 1998).

Indicó además que ya para la época, no era acertado hablar de familia nuclear, esto es padre-madre-hijos, además de matrimonios tradicionales tendientes a perdurar en el tiempo como si fueran los únicos tipos que existen, en tanto que ya ni siquiera en la actualidad este es el modelo de familia "normal", pues la sociedad está siendo ocupada por nuevas clases de familias alternativas. Es por ello por lo que la negativa de reconocer a la familia homosexual en este país provocaba que no pudieran institucionalizarse las transformaciones de esta clase de familias.

Posteriormente, uno de los primeros fallos que reconoció la existencia de familias homosexuales en Argentina se remonta al año 2003, a través del fallo del Juzgado de Primera Instancia de Familia Cuarta Nominación de la Provincia de Córdoba, al resolver un caso en el que una ciudadana reclamaba judicialmente la guarda de sus dos hijos menores, cuya custodia en cabeza del padre de estos. La accionante argumentaba que la conducta sexual no convencional de su ex esposo, quien convivía con una pareja homosexual, ponía en peligro la moral de los niños.

El juez desestimó la pretensión de la parte actora, aduciendo principalmente a los siguientes argumentos: 
- En aquellos casos de conflicto paternal por la tenencia de los hijos menores, debe otorgarse su guarda a quien la ejerció de manera beneficiosa. En este caso, la conducta no convencional del padre de los menores quien convive con su pareja del mismo sexo en habitaciones separadas, no resulta contraproducente ni pone en riesgo el desarrollo de sus hijos, toda vez que el modo de vida y las convicciones religiosas, políticas o ideológicas solo pueden juzgarse cuando inciden de manera negativa en el desarrollo de los menores.

- Cuando se resuelven conflictos suscitados entre padres divorciados por la tenencia de sus hijos menores de edad, no debe hacerse mérito del comportamiento sexual observado por quien detenta la guarda de estos, a menos que dicho comportamiento incida de manera negativa en el desenvolvimiento del menor, pues no implica falta de idoneidad de la función parental, conduciendo la solución contraria a meras especulaciones sin fundamento que podrían convertirse eventualmente en una fuente de discriminación inaceptable.

- El principio que obliga a reconocer la autonomía y la subjetividad del menor en tanto que es sujeto de derechos con capacidad para intervenir en los procesos decisorios sobre su destino dentro de los límites derivados de la condición de sujeto en desarrollo, no implica conferirle poder de decisión en los conflictos que lo involucren, debiendo prevalecer el interés superior de los menores entendido como la satisfacción de todos los derechos que lo asisten como persona, sobre sus deseos y opiniones. (Nofal, 2010).

Luego, desde el año 2008 comenzó en el país un fuerte debate sobre la necesidad de aprobar la figura del matrimonio entre parejas del mismo sexo, como una forma de garantía a estas parejas para que se hicieran extensibles los mismos derechos de las heterosexuales, a saber, la libertad para elegir un compañero de vida, unirse con esa persona en un compromiso oficialmente reconocido y formar una familia que se adapte a los nuevos contextos sociales que se desarrollaban en el país, y que esta fuera, además protegida a través del disfrute de todos los derechos constitucionales derivados del matrimonio civil.

Esta cuestión finalizó el 5 de mayo de 2010, cuando la Cámara de Diputados aprobó un proyecto de ley modificatorio del Código Civil que permitió el matrimonio entre personas del mismo sexo y la adopción, con los mismos requisitos que ya existían para las parejas heterosexuales. Este cambio legislativo supuso también modificar la Ley 24.779 de 1997, que regula los requisitos, trámites y modalidades de adopción en todo el ámbito del territorio; ello, sin embargo, varía de acuerdo con los requisitos exigidos en cada provincia.

Así, en Argentina, la institución de la adopción homoparental fue el resultado de la aprobación de la Ley del Matrimonio Igualitario, toda vez que era necesario adecuar las disposiciones del ordenamiento jurídico argentino con la real transformación del concepto de familia.

Brasil: aplicación del principio "lo que no está prohibido está permitido constitucionalmente"

Para el Supremo Tribunal de Justicia de Brasil, la familia es merecedora de la protección del Estado, así sea conformada por personas del mismo sexo, pues si de ambos intervinientes se predica la permanencia y la intención de continuar con la familia, no existe en el ordenamiento jurídico ninguna disposición que impida la posibilidad de la adopción. 
Esta posición ha sido defendida por diversos sectores doctrinales del país con base en el principio de legalidad consagrado en el artículo 5 inciso II de la Constitución Federal según el cual "nadie estará obligado a hacer o dejar de hacer algo sino en virtud de la ley"; señalan además que, si no existe un Estatuto del Niño y el Adolescente en el cual se restrinja explícitamente la adopción, las parejas homosexuales también podrían adoptar. (Gonçalves Paraviso, 2012)

La Constitución brasilera prohíbe en su artículo $3^{\circ}$ toda clase de discriminación, incluso aquella proveniente de la orientación sexual, sin embargo, la realidad evidencia que la homosexualidad aún sigue siendo estigmatizada y perseguida; por esta razón las personas homosexuales han recurrido a la adopción de menores a través de solicitudes individuales, con el fin de evitar las trabas que el sistema pueda imponer.

En Brasil, como la adopción por parte de parejas homosexuales no estaba regulada por la ley, muchos homosexuales optaron, inicialmente, por formalizar la guarda única del menor (en portugués guarda única da criança), configurándose entonces un caso de monoparentalidad. En algunos casos, luego del proceso adoptivo el menor pasar a ser criado también por el compañero/a del adoptante. (Silva Cecílio, Scorsolini-Comin, \& Antônio dos Santos, 2013).

La adopción homoparental ha sido aprobada en sentencias aisladas de los tribunales federales y el Supremo Tribunal Federal que han resuelto casos concretos sobre esta materia, sin embargo, no existe un consenso o trato igualitario a todos los casos que se presentan; estos se resuelven siempre bajo la discrecionalidad del juzgador. Por su parte, el Código Civil brasilero no hace ninguna mención respecto al sexo de los padres adoptantes, por lo cual se ha interpretado el contenido de este capítulo bajo la consigna "lo que no está prohibido, está permitido".

El primer caso de adopción homoparental en el país data del año 2005, a través de la sentencia del 11 de noviembre de 2005 en la ciudad de Bagé, Estado de Rio Grande do Sul, en el que un juez de la Niñez y la Juventud, falló por primera vez a favor de la adopción por parte de parejas del mismo sexo en este país. Se trataba de una pareja de lesbianas, quienes, tras una relación de siete años, decidieron adoptar dos hermanos pues habían estado a cargo de uno de ellos desde que nació. En aquella ocasión el juez argumentó que la sociedad no puede negar la existencia de parejas del mismo sexo, a las que calificó como un determinismo biológico, más que una simple opción sexual; por esta razón, estimó que la creación de un ambiente de afecto en el que los niños van a vivir cumple con todos los requisitos suficientes que muchas veces no pueden predicarse de aquellas parejas consideradas "normales". De esta manera, el juez descartó la posibilidad de que la convivencia de los menores con personas homosexuales pudiese influir en su opción sexual, toda vez que, si ello fuera verdadero, no existirían personas homosexuales dentro de familias constituidas por personas heterosexuales.

Este fallo histórico fue considerado como uno de gran trascendencia, puesto que por primera vez se permitió una adopción de este tipo. Para el presidente del Instituto Brasileño de Derecho de Familia (IBDFAM), Rodrigo Pereira da Cunha, esta decisión representó una evolución del Derecho de Familia y,

Esto ayuda a avanzar en un área donde no se puede avanzar por medio de la legislación, toda vez que en la actualidad no existe una ley sobre matrimonio 
igualitario y adopción en el país, por lo que todos los casos se han resuelto a través de la vía judicial". (De salles \& De Oliveira Nusdeo, 2009).

Otros Estados del país también han reconocido la homoparentalidad; María Berenice Días, ex Magistrada de la Corte Suprema de Rio Grande Do Sul, ha sido enfática en reconocer las uniones estables entre homosexuales. En su opinión: “dado que las relaciones heterosexuales y homosexuales no son diferentes, las mismas normas jurídicas deben ser aplicadas por analogía. (...) ni siquiera la literatura de vanguardia cree que sea posible aplicar la legislación de familia debido a la redacción de la Constitución".

En aquella oportunidad manifestó también que:

Existe una gran resistencia para aceptar la posibilidad de que las parejas homosexuales puedan adoptar. Hay una creencia equivocada de que la falta de referencias sobre el comportamiento de personas del mismo sexo pueda acarrear secuelas psicológicas y dificultad en la identidad sexual del menor adoptado. Sin embargo, teniendo en cuenta diversos estudios llevados a cabo con parejas homosexuales que tienen hijos, no existen evidencias que permitan concluir que los menores puedan sufrir disturbios o desvíos en sus conductas sexuales por el simple hecho de tener dos padres o dos madres no se han encontrado efectos dañinos en el normal desarrollo y la estabilidad emocional de los menores que tienen padres del mismo sexo, por lo que no puede negarse la posibilidad a estas parejas de conformar una familia. (Kochhann Scheeren \& Hahn, 2016). Sin embargo, no admite qué cambios son necesarios en las normas jurídicas antes que este derecho sea solicitado ante los tribunales de familia. (Ordóñez Daza \& Valencia Valencia, 2012).

Finalmente, con el objetivo de elevar la institución homoparental a ley federal, en el año 2010 la Comisión de Constitución y Justicia presentó el Proyecto de la Ley Nacional de Adopción para reglamentar la adopción de parejas homosexuales. Su objetivo era "priorizar el derecho de los niños y adolescentes a la convivencia familiar establecido en el Estatuto del Niño y Adolescente", innovando así en la ampliación de un concepto de familia, que comprendía a todos aquellos con quienes el menor mantuviera vínculos de afinidad y afecto. (Kochhann Scheeren \& Hahn, 2016). Posteriormente, cuando fue sometido para su aprobación en la Cámara de Representantes, la parte del texto que contenía la autorización para la adopción de niños y adolescentes por una pareja del mismo sexo fue retirado, motivo por el cual el Proyecto de Ley perdió su esencia.

Uruguay: en el ordenamiento jurídico prima el interés superior del menor y el derecho a pertenecer a una familia.

Desde el año 2008 la ley uruguaya equiparó los derechos y obligaciones del matrimonio con los de las parejas heterosexuales u homosexuales que convivan por más de cinco años, lo cual incluía además otras disposiciones vinculadas principalmente al ámbito de la seguridad social.

En el año 2009 se aprobó la Ley 18.950 por la cual se modifican las disposiciones relativas a la adopción como parte de una modificación al Código de la Niñez y la Adolescencia; ello, fue el resultado de múltiples intereses y una fuerte participación de los colectivos LGBTI del país; el nuevo texto legal tiene une perspectiva inclusiva que ubica en igualdad de oportunidades a los sujetos, respetando su orientación afectivo-sexual y la identidad de género (Clavero Lerena, 2014). 
En ella, se habilitó a las parejas con cuatro años de unión civil o concubinato (incluyendo también las homosexuales) a solicitar la adopción de un menor. La ley modificó disposiciones del Código de la Niñez y la Adolescencia y centralizó "el control de las inserciones de niños/as en familias cumpliendo así con los fines de la adopción propuestos por el Instituto del Niño y el Adolescente del Uruguay (INAU) y el Poder Judicial". Al igual que en Argentina, la Ley indicaba que nadie podría ser adoptado por más de una persona a no ser que fueran dos cónyuges o concubinos, sin embargo, la disposición no regía para los esposos divorciados y para los ex concubinos siempre que mediará la conformidad de ambos y cuando la guarda o tenencia del niño, niña o adolescente hubiera comenzado durante el matrimonio o concubinato y se completara después de la disolución de éste. El Senado de la República argumentó que dicha norma lo único que buscaba es adecuar la ley a los derechos infantiles y de este modo evitar las irregularidades que existen en la actualidad, donde muchos niños son entregados de forma negociada, fomentando el tráfico de menores en la región.

Así, la nueva legislación permite que a los niños y adolescentes que se encuentren en condiciones de adoptabilidad se les restituyan sus derechos a vivir con una familia. De esta manera y a través de ese texto ambiguo, Uruguay fue el primer país en Latinoamérica en permitir las adopciones entre parejas del mismo sexo, pero solo en los casos de unión civil, ya que nada se reguló acerca del matrimonio igualitario.

Posteriormente, en noviembre del año 2012 comenzó en el Congreso el debate acerca de la posibilidad de dar camino libre al matrimonio por parte de las parejas homosexuales, siendo aprobada en abril del 2013 la Ley 19.075, que otorgó idénticos derechos en materia de adopción y reproducción asistida tanto a las parejas heterosexuales como homosexuales, equiparando los derechos y obligaciones sin importar la identidad sexual o de género.

Con relación a quienes están facultados para adoptar, es necesario comprender que quien sea adoptante, debe tener claro que, existiendo uno o más integrantes de la familia de origen del menor, con quien este tuviere vínculos significativos, el adoptado podrá conservar esta relación. El niño tendrá siempre derecho a mantener los lazos con su familia de origen si se estima que existen las condiciones necesarias para ello. (Clavero, 2014).

Si la adopción en cambio se realiza por parte del nuevo cónyuge o concubino del padre o madre biológico del menor, dentro o fuera del matrimonio, la adopción será posible siempre y cuando el niño o adolescente haya perdido todo vínculo con su otro progenitor. Por último, la ley también agrega que toda persona que inicie un proceso de adopción debe ser mayor de 25 años, y tener una diferencia de al menos quince años con el menor que pretende adoptar; sin embargo, eventualmente el juez podría analizar estos casos a fin de considerar si es justificable o no la adopción por no cumplir con este último requisito. Posterior a la aprobación de la adopción de un menor por el juzgado de familia, el Departamento de Adopciones del Instituto del Niño y del Adolescente de Uruguay, a través de un equipo técnico determinan la aptitud para la adopción y la familia a asignar en cada caso, según parámetros técnicos y criterios científicos. Luego, El Instituto dará la aprobación final. Con la sentencia otorgada por el juez, los padres efectúan la inscripción de su hijo en la Dirección General del Registro de Estado Civil. Si los padres no están casados, el menor se inscribe como fuera de término, en cambio si son cónyuges se inscribe como hijo dentro del matrimonio y como reconocidos dentro del mismo. 
A partir de la promulgación de la ley uruguaya, son pocos los casos de adopción conocidos en el país. Con todo, hay un caso relevante en el año 2013, en el que una juez concedió la adopción de una menor de dos años a una pareja de lesbianas que formalizó su unión concubinaria (Figura adoptada en la Ley 18.246 de 2007) luego de la aprobación del matrimonio. La pareja se presentó ante la justicia para tramitar la adopción de la menor, hija biológica de una las reclamantes, concebida a través de un proceso de inseminación intrauterina. La juez en su sentencia indicó que la pareja conformaba una familia y constituían un hogar en el que le brindaban a la niña un cuidado afectivo que correspondía a todas sus necesidades; además, reunía todos los requisitos exigidos por la ley.

Entre los argumentos relevantes en este caso, se encuentra la protección del principio del interés superior del menor. En su sentencia, la jueza manifestó que:

El principio del interés superior del niño fue uno de los mecanismos para avanzar en este proceso de considerar el interés del niño como un interés que debía ser públicamente, y por consecuencia, jurídicamente protegido. Por lo tanto, el interés superior del menor es un principio garantista. (Cillero, 1994).

Aunque la adopción sólo ha sido reconocida en estos cinco países, especialmente a través de fallos judiciales emitidos por las Altas Cortes, el debate sobre la homoparentalidad y la igualdad de derechos entre las personas heterosexuales y homosexuales, es un tema relevante y en constante discusión en los demás países y organismos internacionales del continente. La decisión de la Corte Interamericana de Derechos Humanos, al resolver el caso Atala Riffo y Niñas Vs. Chile, está llamada a convertirse en un genuino leading case en relación con la protección jurídica de la homosexualidad en el ámbito regional americano. Lo interesante de la sentencia, es el análisis que introduce la Corte sobre el alcance real de la homoparentalidad en relación con el problema abordado, además de la posibilidad de preguntarnos acerca del precedente que este caso podría suponer en la discusión sobre el tema en nuestro continente.

La Corte analiza el caso de Karen Atala, de nacionalidad chilena, quien contrajo matrimonio en 1993. De esta relación, tuvo 3 hijas. En marzo de 2002 se separó de su cónyuge, acordando que la custodia de las hijas quedaría a cargo de la señora Atala, teniendo el padre derecho a una visita semanal.

En noviembre de ese año, la compañera sentimental de Karen Atala comenzó a convivir con ella y las menores en el domicilio familiar. Por este motivo, el padre presentó una demanda de custodia ante el Juzgado de Menores de Villarrica, considerando que el desarrollo físico y emocional se encontraba en riesgo. Se concedió provisionalmente la custodia al padre, pero rechazó su demanda de tuición ${ }^{6}$, considerado que la orientación sexual de la madre de las menores no representaba un impedimento para desarrollar la maternidad de manera responsable. El padre recurrió a la Corte de Apelaciones de Temuco, en la que concedieron la tuición definitiva.

Posteriormente, Karen Atala llevó su caso a la Corte Interamericana de Derechos Humanos, donde se examina el principio del interés superior del menor conforme al sistema americano de protección de los derechos; la Corte indicó que este es un fin que no puede ser utilizado para discriminar debido a la orientación sexual del padre o madre, especialmente a partir de presunciones infundadas y estereotipadas. En su fallo, la Corte condenó a Chile por violar el derecho a la no discriminación contenido 
en el Pacto de San José, estimando errónea la decisión de la Corte Suprema de Chile, porque la expresión de la opción sexual de la madre no debería ser un antecedente relevante para determinar su idoneidad como titular del cuidado personal de sus hijas. Concluyó también que la Convención Americana sobre Derechos Humanos no protege un único modelo de familia.

Como se observa, esta sentencia ofrece un marco exegético muy claro y relevante en defensa de la igualdad de las personas homosexuales. La Corte Interamericana resalta que "la valoración social de la homosexualidad va cambiando y los estados y sus ordenamientos deben ayudar a ese cambio social y no a legitimar y consolidar formas de discriminación lesivos de los derechos humanos". (Martínez, 2014).

Introduce, además, un interesante giro argumentativo respecto a las supuestas consecuencias que tienen para los menores convivir con una familia homoparental. En este punto la Corte se pregunta: ¿Perjudica de algún modo a los menores la convivencia con parejas del mismo sexo? Para responder a este interrogante, se debe invertir la carga de la prueba de modo que no es la presunta víctima (para el caso concreto Karen Atala) quien debe mostrar que su conducta no perjudica a nadie, sino que debe ser la autoridad que limita o restringe el derecho a no sufrir discriminación por orientación sexual quien debe mostrar el daño.

En general, la Corte Interamericana de Derechos Humanos realizó en el Caso Atala un examen de igualdad desde la base de un principio antidiscriminatorio con base en la condición sexual; todo ello supuso un avance porque agrega una perspectiva de igualdad como reconocimiento. Esta idea, busca resolver el problema de la formación de la subjetividad apuntando a los déficits que fracturan a la sociedad en subjetividades dominantes y dominadas. (Clérico, 2013). Sin embargo, la sentencia no hizo referencia a un tema fundamental frente al debate de la adopción homoparental, que, como se explicará más adelante es el mayor vacío al que se enfrenta la discusión actual sobre el tema en el continente latinoamericano; este es el principio de interés superior del menor. La omisión de la Corte para referirse al principio del interés superior del menor sintetiza la cuestión debatida en que la decisión de tuición de las menores estuvo fundada en prejuicios y estereotipos vinculados a la homosexualidad, y no obedece realmente a los intereses de las tres menores. Así, el debate versó sobre la reivindicación de la condición homosexual y la legitimidad de su expresión por parte de la madre de las menores, argumento que merece todo el esbozo y análisis, pero que resulta insuficiente, si no se tiene a su vez en cuenta la protección de los menores y sus garantías mínimas de cuidado, afecto y derecho a pertenecer a una familia.

Uno de los puntos trascendentales de este caso dentro del debate de la adopción homoparental, es la referencia especial que hace la Corte a uno de los pilares básicos de la adopción; para empezar, la Corte IDH sostuvo que el principio del interés superior del niño tiene como fundamento la dignidad humana. Indicó además que, en casos relativos a la custodia de menores de edad, la decisión sobre que está en el mejor interés del niño ha de hacerse con base en la evaluación de los -comportamientos parentales específicos y su impacto negativo en el bienestar y desarrollo del niño según el caso, los daños o riesgos reales y probados, y no especulativos o imaginarios. (Gómez \& Velázquez, 2012).

De esta manera, bajo el imperio de la Convención Americana, la protección del principio del interés superior del niño ha de ser argumentada, no pudiendo sostenerse 
que se busca dar vigencia a dicho principio, en desmedro de derechos de terceros, sin cumplir con una carga de fundamentación suficiente donde se acredite que con la decisión tomada por el operador jurídico se está protegiendo al niño de una afectación real a su desarrollo y bienestar. (Gómez \& Velázquez, 2012).

Con todo la Corte considera (a buen juicio) que en la región se hace urgente y necesario comenzar a implementar programas y cursos permanentes de educación y capacitación en derechos humanos, orientación sexual y no discriminación, protección de los derechos de la comunidad LGBTI (lesbianas, gays, bisexuales, transexuales e intersexuales), además de una fuerte necesidad de superación de los estereotipos de género en contra de esta población; todo ello, supone grandes retos aún para América Latina.

Este caso, si bien no se presentó en uno de los países objeto de análisis del presente texto y se omitió uno de los más importantes y fundamentales argumentos para permitir la adopción homoparental (este es, el interés superior del menor), la sentencia ha servido como criterio interpretativo para el resto de los países latinoamericanos. El tema, hace referencia al carácter de la jurisprudencia en el ámbito internacional. Si bien la jurisprudencia se reserva por lo regular a casos dentro de los Estados, trasladándose al ámbito internacional, podría afirmarse que similar definición recibirían los criterios derivados de la actividad de los órganos jurisdiccionales creados en ese espacio; se proyecta entonces en dos sentidos, por un lado, comprende la posibilidad de utilizar los criterios derivados de la decisión de casos en el fallo de otros similares, en el ámbito interno. Por otro lado, hace mención a la libre discreción de los operadores jurídicos del ámbito para utilizar estos argumentos en sus fallos cuando los argumentos que versan sobre la decisión del órgano internacional puedan ser similares al que se debate en el ordenamiento jurídico interno.

El mayor aporte que el caso arroja al debate de la adopción homoparental en el continente, es la necesidad de implementar programas, acciones y cursos en el marco de políticas públicas, para educar a la población y especialmente a los funcionarios judiciales en las teorías de género, derechos humanos y sexualidad diversa; el caso, desarrolla además un discurso argumentativo basado en postulados de igualdad. Por este motivo, los Estados latinoamericanos podrían reconocer y adecuar sus líneas jurisprudenciales de derecho interno, siguiendo las decisiones y recomendaciones de los órganos del sistema interamericano de derechos humanos; esta es notablemente una de las aspiraciones y compromisos de la región.

\section{La adopción homoparental en el ordenamiento jurídico colombiano: breve recorrido por la jurisprudencia de la Corte Constitucional sobre el paulatino reconocimiento de la homoparentalidad}

Desde hace aproximadamente 12 años, la Corte Constitucional colombiana ha introducido en sus diversos fallos argumentos que permiten comprender mejor los alcances del artículo 42 de la Constitución Política que trata sobre la familia, especialmente sobre aquellos vínculos de los que se deriva un reconocimiento y especial protección por parte del Estado.

Sin embargo, a pesar de evidenciar una consonancia hermenéutica hasta el año 2007, la Corte abruptamente rompe con esta línea interpretativa y comienza a dar alcances diferentes a los conceptos contenidos en el artículo 42 que la Constitución presenta respecto a la fundación nuclear de la familia, dando paso a que las parejas homosexuales, se asimilen completamente, en lo que les pueda corresponder, 
a las uniones heterosexuales que consiguen fundar un vínculo familiar a través del compromiso responsable y la apertura a una comunidad doméstica de crianza y fraternidad.

La Corte introduce de esta manera un nuevo parámetro bajo el supuesto de que, siendo guardiana de la Constitución y en su deber de interpretarla, indica cómo debe haber una especial protección por parte del Estado a la decisión libre y responsable de las parejas del mismo sexo a conformar una familia.

Por este motivo, en este punto es menester analizar las sentencias que ha proferido la corporación referentes a la adopción por parte de parejas del mismo sexo y el desarrollo de estas decisiones, toda vez que, en nuestro país los avances que versan sobre este tema se han logrado a través de fallos jurisprudenciales.

Un camino dividido entre la reivindicación de los derechos de las parejas homosexuales y el concepto tradicional de la familia colombiana.

A partir del año 1995 la Corte Constitucional ha emitido diversos pronunciamientos sobre la adopción por parte de personas homosexuales (de forma individual y en pareja). La primera sentencia emitida sobre este punto es el fallo de tutela T-290 de dicho año.

En esta sentencia, se resuelve el caso de un hombre que solicitó al ICBF la adopción de una menor que había cuidado desde el momento en que sus padres biológicos la abandonaron; el ICBF determinó que el medio en el que vivía la menor no era apropiado para su normal desarrollo y concluyó que no podía quedarse con el actor dadas las condiciones precarias en las que habitaba. Tiempo después, y al ver que las condiciones del solicitante no mejoraban, el ICBF decidió que la niña debía ser dada en adopción a una familia, decisión a la que el actor se opuso y expresó su desacuerdo con buscar otra familia para ella porque a pesar de su pobreza, durante cinco años él la había cuidado y querido como una hija. Indicó que la única razón por la que se tomó esa decisión era por su condición homosexual, circunstancia que no le impedía ser un buen padre. Por las razones anteriores consideró violado su derecho a la igualdad y el de la menor a pertenecer una familia.

En el fallo de instancia se negó la petición por considerar que existían otros medios judiciales de defensa al alcance del actor, además que no se evidenciaba violación alguna a los derechos fundamentales alegados.

Al analizar este caso, la Corte Constitucional decidió confirmar la sentencia de primera instancia considerando que la acción de tutela como mecanismo transitorio no podía ser invocada en este caso porque sólo procedía cuando se trata de evitar un perjuicio irreparable. Indicó además que, a falta de los padres o de las personas legalmente obligadas al cuidado de la menor, le corresponde al Estado velar por su custodia y bienestar, o confiarlo mediante la adopción a personas idóneas de acuerdo a lo establecido en la Constitución: en el caso particular era evidente que aunque el actor le brindó cuidado a la menor durante varios años, ella tiene derecho a gozar de la asistencia necesaria para lograr un adecuado desarrollo físico, mental, moral y social de acuerdo al artículo 44 superior.

El tutelante aseguró que su homosexualidad fue el único factor que el ICBF consideró para declarar que la menor se encontraba en estado de peligro y asignar su custodia a 
terceros. En este punto, la Corte hizo énfasis en su parte motiva, que, según el acervo probatorio del caso, se encontraba probada la necesidad de aplicar las medidas de protección adoptadas debido a que las condiciones de habitación de la menor no eran aptas para garantizar su adecuado desarrollo y que en ningún caso la razón de la decisión versaba sobre la orientación sexual del actor.

Sin embargo, en aquella ocasión el Magistrado Carlos Gaviria Díaz salvó su voto, manifestando que esta sentencia no se refería específicamente al establecimiento de un precedente doctrinario e interpretativo en cuanto a la adopción por parte de personas del mismo sexo, dado que la Corte solo se limitó a explicar porque en ese caso no había discriminación y de cualquier manera evitó referirse sobre el tema. El Magistrado indicó que: "Negarle a una persona la posibilidad de adoptar o cuidar a un niño, por la sola razón de ser homosexual, constituiría ciertamente un acto discriminatorio contrario a los principios que inspiran nuestra Constitución". (Corte Constitucional colombiana, 1995).

Posteriormente, resuelve la Sentencia C-814 de 2001, en la que se demandó la inconstitucionalidad parcial de los artículos 89 y 90 numeral $2^{\circ}$ del Decreto Ley 2737 (antiguo Código del Menor) en lo referente a la exigencia de una idoneidad moral del adoptante o adoptantes y la exclusión de las parejas homosexuales como sujetos pasivos de la ley demandada en la lista de posibles adoptantes.

En este caso, la Corte debía definir si el legislador podía o no establecer exigencias de carácter moral a las personas que pretenden adoptar un menor, y si la adopción homosexual resultaba conforme a la Constitución.

En el examen de constitucionalidad la Corte encontró que ambos artículos eran acordes con la Constitución, bajo los siguientes argumentos: frente al artículo 89 del Código del Menor afirmó que la jurisprudencia de la Corporación había precisado que dentro de un Estado pluralista y democrático como figura en la Constitución, el Estado podía adoptar conceptos morales para definir situaciones jurídicas o para limitar algunos derechos de las personas, solo si estos se referían a la moral social o moral pública entendida como aquella comúnmente aceptada. Dicho esto, consideró que la exigencia de idoneidad moral contenida en este artículo para quienes pretendían adoptar no estaba en contra de la Constitución, siempre y cuando dicha exigencia se entendiera referida a la noción de moral social o moral pública.

Asimismo, manifestó que el numeral $2^{\circ}$ del artículo 90 no era violatorio de la Constitución, porque en él se reflejaba la igualdad de trato para las parejas conformadas entre un hombre y una mujer unidos por matrimonio o unión marital de hecho, así se equiparaban los derechos de unas y otras como fue el propósito del constituyente. Ahora, frente a la posible omisión legislativa, a juicio de la Corte no existía tal, ya que la adopción es la forma de satisfacer el derecho de un menor a tener una familia y, la familia que el constituyente protegía es la heterosexual y monogámica.

Con este fallo no se logró que la Corte realizara un análisis riguroso sobre la posibilidad de permitir que parejas homosexuales adoptaran, simplemente se limitó a realizar un estudio de las normas de forma literal y, la intención del constituyente de proteger la familia heterosexual dejando de lado el debate actual de la evolución que ha tenido esta institución y el hecho que la misma ya no sé acopla a la normatividad que concebía la familia como la que se compone de la voluntad de un hombre y una mujer de conformarla. 
En aquella ocasión los Magistrados Manuel José Cepeda Espinosa, Jaime Araujo Rentería, Jaime Córdoba Triviño y Eduardo Montealegre Lynett salvaron su voto, ya que diferían con la interpretación literal del artículo 42 de la Constitución Política en cuanto a que ésta, semánticamente y de la mano con una interpretación holística, reconocía la existencia de varios tipos de familia.

Estos salvamentos y aclaraciones de voto dejaron claro que la Corte evadió realizar un análisis profundo de la posibilidad que las parejas del mismo sexo pudieran adoptar y le dio más importancia a resaltar el concepto de familia monogámica y heterosexual que trae la Constitución dejando por fuera a las parejas homosexuales y creando así en la sociedad la idea de que la familia heterosexual es la que debe prevalecer y es la ideal.

Los Magistrados, consideraron que no era correcto el análisis realizado por la Corte en esta sentencia, toda vez que se hizo una interpretación puramente literal de la norma en la que se concluyó que la Constitución sólo protegía la familia monogámica y heterosexual. Discurrieron que de la lectura del inciso primero del artículo 42 no se podía deducir tal afirmación, pues la estructura gramatical del texto planteaba casos distintos en los que se podía conformar una familia y todos estaban precedidos por la preposición "por". Por esta discrepan con que a lo largo de la sentencia la Corte hubiese sostenido que el único tipo de familia reconocido y protegido por la Constitución es la que se encontraba conformada por un hombre y una mujer.

También consideraron que la Corte no tuvo en cuenta el derecho superior del niño cuando realizó el análisis de la sentencia, aunque en el recorrido de la misma se hizo referencia a esta institución.

Fallo inhibitorio por ineptitud sustancial de la demanda: razón por la cual la Corte Constitucional no realizó un examen riguroso sobre la adopción por parte de parejas del mismo sexo.

Luego, la sentencia C-802 de 2009 versó sobre la inconstitucionalidad del artículo 68 de la Ley 1098 de 2006 por la cual se expide el Código de la Infancia y la Adolescencia y el artículo $1^{\circ}$ de la Ley 54 de 1990.

En este caso, Intervinieron en la sentencia ciudadanos, entidades públicas y privadas, de corte nacional e internacional, e instituciones académicas, apoyando, en su mayoría, la declaratoria de exequibilidad condicionada de los apartes demandados, basando su postura en una interpretación inclusiva de las parejas homosexuales, además de ponderar el principio de interés superior del menor, toda vez que:

en cuanto se refiere al derecho de los niños a tener una familia, la adopción de menores por parte de parejas homosexuales, contrario a lo que podría llegar a pensarse, no afecta el interés superior de éstos y materializa la protección y realización de algunos de sus derechos fundamentales. (...) pareciera entonces que no existe razón suficiente que niegue la posibilidad de que un menor sea entregado a una pareja homosexual, teniendo en cuenta para ello que el funcionario administrativo encargado de la totalidad de los trámites para llevar a cabo una adopción, realiza, en cada caso, una ponderación sobre la idoneidad y estabilidad de la pareja, en orden a procurar la materialización del principio del interés superior del menor." (Corte Constitucional colombiana, 2009). 
A pesar de ello, la Corte profirió un fallo inhibitorio debido a la ineptitud sustantiva de la demanda, por no incluir dentro de los apartes a examinar constitucionalmente toda la normatividad relativa a la adopción por parte de compañeros permanentes, planteando el régimen jurídico al respecto diferentes supuestos de hecho cuyo análisis implicaba pronunciamientos de fondo en conjunto para garantizar que los efectos de la sentencia no fueran inocuos y que se respetara el debido proceso constitucional al permitir la intervención de interesados u obligados a rendir concepto en lo referente a lo normatividad que se vería afectada con un fallo modulativo ${ }^{7}$.

Introducción del argumento hito las parejas homosexuales también son familia: Sentencia C-577 de 2011.

En esta ocasión se demandó el artículo 113 del Código Civil el cual establecía el matrimonio como aquel conformado por un "hombre" y una "mujer". Se solicitó que dicha interpretación se hiciera extensiva a las parejas del mismo sexo eliminando la procreación como uno de sus fines; asimismo, las definiciones de familia dadas por las leyes 294 de 1996 y 1361 de 2009, de acuerdo a su interpretación, excluyente de las parejas homosexuales.

La Corte declaró la exequibilidad del artículo 113 del Código Civil bajo el precepto que enmarcó a este vínculo contractual supeditado a la unión heterosexual por voluntad expresa del legislador sin desconocer el déficit de protección existente respecto de las parejas homosexuales; exhortó al legislador, dentro de un marco temporal definido a que expidiera normas que regularan el vínculo contractual de las parejas del mismo sexo, so pena de aplicar la regulación existente para las parejas heterosexuales al vencimiento del término de 2 años.

Uno de los argumentos introducidos para fundamentar su decisión fue que el concepto de familia establecido en la Carta Política no era excluyente de formas distintas de conformación de vínculos familiares a la unión marital o matrimonio heterosexual monogámico ya que, según la evolución del núcleo social referido y la maleabilidad del mismo debido a los cambios en la estructura de la sociedad, era posible reconocer vínculos diferentes a los consagrados en el artículo 42 de la carta magna. Aclaró que, en concordancia con esta interpretación respecto al precedente establecido por el ente judicial sobre la familia como heterosexual y monogámica, el concepto se hacía extensivo a las parejas homosexuales debido a que comparten vínculos de afecto, respeto y solidaridad reconocida en las uniones heterosexuales.

Posteriormente, al referirse sobre la adopción, aclaro que, según lo indica la doctrina, por más que se estén materializando los derechos del adoptante a tener una familia como núcleo de la sociedad en virtud del artículo 42 de la Carta Política y los ya mencionados anteriormente, como el libre desarrollo de la personalidad y la igualdad ante la ley resultando en el derecho a no ser discriminado por la orientación sexual, bien sea de forma consentida o conjunta, el núcleo de la figura jurídica creadora de relaciones de parentesco reside primordialmente en la materialización de los derechos fundamentales del menor sujeto a la adopción, a saber: el derecho a la vida en condiciones óptimas para garantizar su adecuado desarrolo, estableciendo a la familia como pilar fundamental de los derechos de los niños, niñas y adolescentes

7. De acuerdo con lo señalado por la Corte Constitucional en su sentencia C1153/05 Magistrado Ponente Marco Gerardo Monroy Cabra, la modulaciónn del fallo constitucional no se refiere sino a la adecuación teórico jurídica de la norma infraconstitucional con la disposición superior. Dicha práctica en manera alguna implica un pronunciamiento sobre las connotaciones políticas de la disposición bajo estudio. Pese a que la Corte declara exequible la norma analizada bajo la condición de que se entienda que su interpretación constitucional es aquella y no ésta, el juez constitucional jamás abandona el terreno del análisis jurídico. 
en la legislación nacional (artículo 1 de la ley 1098 de 2006); en nuestra Constitución en virtud del artículo 44 donde se establece el derecho de los sujetos pasivos de la norma específica a tener una familia y en la internacional, en la Convención de los derechos del niño, tratado internacional ratificado por Colombia (en su preámbulo y artículos iniciales que establecen principios rectores en el comportamiento que debe tener el estado).

Por lo anterior concluyó que, en nuestra Constitución Política, más específicamente los artículos 13 y 44, consagran un interés superior y más imperioso constitucionalmente a los derechos de aquellos que requieran especial protección del Estado debido a su incapacidad o estado de inferioridad, materializándose especialmente en los menores de edad. Es imperante señalar que el Código de la Infancia y la Adolescencia establece, de manera expresa, como criterios interpretativos en la aplicación al ámbito regulado por la ley, la preponderancia de lo establecido en sí mismo, con respecto a derechos de igual o menor rango constitucional (artículos 8 y 9). De lo expresado surge entonces la innegable conclusión que por mandato legal, constitucional y doctrinario prima el derecho del menor adoptable sobre el del posible adoptante.

En esta sentencia la Corte Constitucional concluye que no puede existir un concepto único y excluyente de familia, identificando a ésta solamente con aquella que surge de un vínculo matrimonial. Por ello determinó que la heterosexualidad no es, entonces, elemento esencial del concepto de familia, pues no se predica de todas ellas.

Sentencia T-276 de 2012: La Corte concede la tutela, pero guarda silencio frente a los derechos solicitados por el accionante para sus hijos y para sí mismo.

En esta ocasión, un ciudadano estadounidense interpuso una acción de tutela en nombre propio y de sus hijos adoptivos menores de edad, en contra del Instituto Colombiano de Bienestar Familiar (ICBF), solicitando que se protegieran sus derechos fundamentales a la igualdad, al libre desarrollo de la personalidad, al debido proceso, así como el derecho de los niños a tener una familia y a no ser separados de ella y a no ser discriminados por su origen familiar.

El actor inició un proceso de adopción de dos menores de 13 y 8 años, el cual culminó satisfactoriamente. Antes de salir del país con sus hijos se acerca a las oficinas del ICBF para despedirse de algunas personas y afirma que en una conversación informal y sin traductor le manifiestó a la Subdirectora de Adopciones de la entidad que siendo él una persona gay y con los temores que se presentan en el país frente a la adopción por parte de personas homosexuales, nunca fue considerado no apto para adoptar; la funcionaria le preguntó si tenía pareja y él respondió afirmativamente.

A raíz de esto el ICBF solicitó impedir la salida de los menores del país e inició un proceso de restablecimiento de derechos de los menores. El demandante consideró que era evidente que la Institución le estaba dando un trato diferenciado por su orientación sexual.

El ICBF afirmó que en el caso no había lugar a proteger los derechos de los niños a tener una familia porque no existía una y al respecto, señaló "(...) cuando una persona homosexual, sea una mujer o un hombre ó una pareja homosexual decide solicitar una adopción, desde la simple perspectiva exegética y literal de la Constitución, no constituyen familia" (Corte Constitucional colombiana, 2012). 
Tanto la sentencia de primera y de segunda instancia negaron el amparo solicitado por el actor, entre otras razones, al considerar que el demandante no fue discriminado por las acciones desplegadas por el ICBF, a su juicio, la institución buscaba proteger el estado emocional de los niños.

A consideración de la Corte Constitucional, la tutela era procedente porque el accionante no contaba con otros medios para evitar un perjuicio irremediable y por lo tanto la concedió, pues a su juicio, el ICBF tomó decisiones injustificadas y desproporcionadas que constituían una vía de hecho administrativa y lesionaron los derechos fundamentales al debido proceso y a la unidad familiar. Es menester indicar que la Corte no se pronunció sobre los derechos a la igualdad y al libre desarrollo de la personalidad que el adoptante había solicitado, así como el derecho de los niños a tener una familia y a no ser separados de ella y a no ser discriminados por su origen familiar.

En esta sentencia se observa (como en muchos otros pronunciamientos de la Corte Constitucional) que no existe una verdadera decisión de fondo; nada se dice sobre los derechos del accionante, ni se crea un verdadero precedente en la protección de la institución homoparental como una forma de constituir familia; mucho menos se pronuncia sobre el interés superior del menor, especialmente en un país donde muchos niños quedan a disposición del Instituto Colombiano de Bienestar Familiar, quien niega, basándose en estereotipos sociales, la posibilidad a estos menores de pertenecer a una verdadera familia.

La Corte, es aún bastante reservada y a nuestro juicio, temerosa al pronunciarse sobre la adopción entre parejas del mismo sexo, tema que requiere un profundo análisis, y más que ello, la adopción homoparental en Colombia es un tema que aguarda, desde hace más de 10 años, posiciones sólidas, y en todo caso una verdadera regulación, pues en esta sentencia se evidencia el vacío jurídico que existe al respecto.

Para la Corte, la interpretación de improcedencia de la solicitud de adopción del hijo biológico por parte de la compañera sentimental del mismo sexo de la madre es totalmente contraria a los principios rectores del ordenamiento jurídico colombiano y por lo tanto debe evitarse en el proceso la discriminación con fundamento a la orientación sexual.

En sentencia SU-617 de 2014, se resuelve el caso de Ana Elisa Leiderman y Verónica Botero (conocidas en la sentencia como Turandot y Fedora) frente a la pretensión de adopción de la menor Lakme hija de una de las accionantes.

El 06 de enero de 2009 la pareja presentó una solicitud de adopción ante la Defensoría de Familia de Rionegro, posteriormente esta entidad declaró la improcedencia de la petición arguyendo que la regulación vigente permitía la adopción por las parejas del mismo sexo y que de acuerdo con la jurisprudencia no había posibilidad jurídica de autorizar ese tipo de adopción y por lo tanto sólo podría adoptar el hijo del compañero o compañera permanente si fuese una unión heterosexual.

A raíz de la respuesta de entidad, las accionantes interpusieron acción de tutela en la cual solicitaban que se declarara el vínculo filial entre la hija biológica de una de las accionantes y su compañera permanente. La sentencia de primera instancia ordenó al ICBF la continuación de todos los trámites administrativos de adopción, con pleno cumplimiento del derecho al debido proceso, el interés superior de la menor y el derecho a la igualdad. La entidad demandada impugnó el fallo por cuanto consideró que las accionantes contaban con otros mecanismos judiciales para controvertir el acto 
administrativo que puso fin al trámite de adopción, y que la decisión que ella había tomado estaba conforme a la jurisprudencia constitucional y a la normatividad del caso, y que actuaron respetando los derechos fundamentales de las partes involucradas.

En el estudio del caso, la Corte en la sentencia condicionó la adopción por parte de parejas del mismo sexo al hecho de que los cónyuges tuvieran al menos dos años de convivencia; a que el menor adoptado fuera el hijo biológico del compañero del peticionario de la adopción; y a que ésta sea consentida por el padre o madre biológica. En esta ocasión señaló que:

Cuando la autoridad administrativa excluye la posibilidad de la adopción por consentimiento con fundamento en el carácter homosexual de la pareja requirente, vulnera los derechos de todos ellos a la autonomía familiar y a tener una familia, por cuanto se desconoce, sin razón que lo justifique, la existencia de un arreglo familiar en el que el menor, por voluntad de su padre o su madre biológicos, comparte la vida con el compañero o compañera del mismo sexo de aquél, y en el que se conforma un vínculo sólido y estable entre ellos, a partir del cual el adulto ha asumido las obligaciones y deberes asociados al vínculo filial". (Corte Constitucional colombiana, 2014).

Para la corporación, la interpretación de improcedencia de la solicitud de adopción de un niño, niña o adolescente por parte de la compañera sentimental del mismo sexo de su madre biológica cuando medie el consentimiento, es totalmente contraria a los principios rectores del ordenamiento jurídico colombiano. Es por ello por lo que las autoridades administrativas o judiciales deben evitar la discriminación con fundamento en la orientación sexual como criterio para imposibilitar la creación de relaciones materno-filiales. En armonía con este argumento, ordenó continuar con el trámite de adopción, sin que la orientación sexual de la solicitante pudiera ser utilizada como criterio de descalificación para la misma.

Esta decisión sin precedentes concluyó que el criterio de discriminación basado en la orientación sexual es inaceptable en materia de adopción en aquellos casos en que la compañera permanente reclama la autorización administrativa y judicial para adoptar a la hija biológica de su pareja. Con todo, esto no resolvió el vacío sobre el derecho de adopción para las familias con orientación sexual diversa; sirvió sin embargo, como herramienta de acercamiento entre la realidad social y el derecho en clave del principio de igualdad establecido por la condición social del Estado colombiano.

Es menester recordar también que mediante el concepto 5926 del 17 de mayo de 2011 expedido por el ICBF se estableció que no es procedente, de acuerdo a los parámetros constitucionales textuales y al desarrollo interpretativo de la Corte Constitucional, establecer la pregunta sobre la orientación sexual dentro del Lineamiento Técnico del Programa de adopciones, como regulador de las calidades necesarias para acceder a la institución jurídica creadora del parentesco civil, por referirse a criterios discriminatorios amparados bajo el peso de la Carta Política constitutivos del desarrollo de la vida digna en conexidad con el libre desarrollo de la personalidad y circunscritos al ámbito privado del ser humano.

Así las cosas, con esta sentencia se observa que para el país aún no era claro el panorama frente a la adopción por parte de parejas homosexuales; la Corte Constitucional aún no había realizado verdaderos pronunciamientos de fondo, ya que, al 
omitir sentar jurisprudencia como en otras ocasiones lo hiciera en temas álgidos que revisten importancia para la sociedad, lo único que reflejaba era más incertidumbre en el reconocimiento de los derechos de las parejas homosexuales. Partiendo entonces del concepto utilizado por Ferdinand Lassalle, en su texto Qué es una Constitución, los problemas constitucionales no son, en principio, problemas del derecho, sino del poder.

Sentencia C-071 de 2015: Parejas del mismo sexo sólo pueden adoptar cuando la solicitud recaiga en el hijo biológico de su compañero o compañera permanente.

En esta sentencia la Corte resolvió el siguiente problema jurídico: si las reglas existentes sobre adopción conjunta y adopción complementaria o por consentimiento ejercida por compañeros permanentes heterosexuales con una convivencia ininterrumpida de al menos dos años, vulneraban los derechos de los compañeros permanentes del mismo sexo a la no discriminación y a constituir una familia.

La Corte analizó la constitucionalidad de apartes de los artículos 64, 66 y 68 de la Ley 1098 de 2006 y del artículo 10 de la Ley 54 de 1990 y concluyó que estos eran exequibles con la precisión que las parejas del mismo sexo sólo pueden adoptar el hijo biológico de su compañero o compañera permanente. Consideró que las normas sobre adopción conjunta no vulneraban los derechos invocados y que le correspondía al Congreso determinar los efectos de la adopción y quiénes pueden adoptar.

Precisó que el concepto jurisprudencial de familia que trajo la sentencia C-577 de 2011 no implica una extensión automática y uniforme de todos los efectos legales incluida la adopción, institución que debe propender por el interés superior del menor teniendo en cuenta que los derechos de los niños prevalecen sobre los derechos de los demás.

Respecto de la adopción conjunta manifestó que esa institución estaba concebida para suplir necesidades de maternidad y paternidad, es decir, que a esta sólo pueden acudir las parejas heterosexuales y eso no significa una vulneración del derecho a igualdad ni de los preceptos del artículo 42 de la Constitución. Sin embargo, aclaró que esto no significa que exista prohibición constitucional para que el legislador reconozca a parejas del mismo sexo el derecho de adoptar, sino que la opción legislativa actual plasmada en las normas demandadas es permitida y no va en contra de la Constitución.

En cuanto a la adopción complementaria o por consentimiento, sostuvo que cuando el Estado se inhibe de reconocer las relaciones familiares existentes entre niños que tienen una sola filiación (madre o padre) y el compañero permanente del mismo sexo de éste y con el que comparte la crianza, el cuidado y su manutención, puede comprometer los derechos de los niños, niñas y adolescentes, porque con esa omisión se amenazaba el derecho constitucional fundamental a no ser separados de su familia. Por esta razón condicionó la exequibilidad del artículo 64 numeral 50, artículo 66 y artículo 68 numeral 50 de la Ley 1098 de 2006, en el entendido que en su ámbito de aplicación están las parejas del mismo sexo cuando la solicitud de adopción recaiga en el hijo biológico de su compañero o compañera permanente.

La Corte Constitucional aprueba la adopción homoparental: Las parejas del mismo sexo pueden adoptar "conjuntamente" en Colombia 
Finalmente, en sentencia C-683 de 2015 la Corte Constitucional decidió permitir que los niños, niñas y adolescentes del país puedan ser adoptados por parejas del mismo sexo. En aquella ocasión se demandó la constitucionalidad de los artículos 64, 66 y 68 de la Ley 1098 de 2006 (parciales) y el artículo $1^{\text {a }}$ de la Ley 54 de 1990 (parcial), por vulnerar los artículos 13, 42 y 44 de la Constitución Política y algunas normas internacionales.

Además, la Corte reconoció la existencia de una evidente omisión legislativa que desconoce el derecho de los menores a ser adoptados por parejas homosexuales y las interpretaciones constitucionales que hacen algunas autoridades administrativas, como el ICBF y la Procuraduría General de la Nación.

En el análisis del caso, la corporación se remitió a los antecedentes legislativos para determinar que la Ley 1098 de 2006 excluyo la adopción por parte de las parejas del mismo sexo, y que por lo tanto, para realizar el examen de constitucionalidad no consideró pertinente hacerlo a partir desde la presunta omisión legislativa relativa propuesta en la demanda sino desde el alcance de las normas parcialmente acusadas y la exclusión de las parejas del mismo sexo de la posibilidad de participar en los procesos de adopción.

Por lo tanto, la Corte realizó un análisis sobre el interés superior del menor, el derecho a tener una familia y de la adopción como medida de protección del menor, haciendo la advertencia de que el análisis constitucional relacionado con la adopción tiene como eje central el principio del interés superior del menor, lo que no significa, que no se analicen otros derechos y principios de rango constitucionales.

Resalta también que, en los procesos de adopción lo importante no es dar un niño a una familia sino una familia a un niño que la necesita y tiene derecho a ella. Es por esa razón que la Corte debía analizar si la adopción por parte de parejas del mismo sexo afecta o amenaza el desarrollo integral de los menores y para esto hace referencia al derecho comparado, a la evidencia científica y fallos relevantes de tribunales constitucionales.

De tal comparación se evidenció que, desde las pruebas científicas y fallos importantes de los países que aceptan la adopción homoparental, el interés superior del menor no es vulnerado por la homosexualidad de los padres, todo lo contrario, se genera un déficit cuando se niega a un menor en condición de adoptabilidad tener una familia; por lo tanto, cuando excluyen a las parejas homosexuales que conforman una familia de los procesos de adopción se genera un desconocimiento al interés superior del menor representado en su derecho a tener una familia, ya que la adopción es una medida de protección que garantiza el derecho de los menores en estado de abandono, de acuerdo al artículo 44 de la Constitución.

En síntesis, la Corte declaró la exequibilidad de las normas acusadas bajos el entendido que, "en virtud del interés superior del menor, dentro de su ámbito de aplicación están comprendidas también las parejas del mismo sexo que conforman una familia". (Corte Constitucional colombiana, 2015).

La decisión se basó principalmente en los siguientes argumentos:

1. Los estudios científicos y las pruebas aportadas al proceso demostraron que la adopción por parte de parejas homosexuales no genera afectaciones en el desa- 
rrollo integral de los niños adoptados y que no está acreditada afectación alguna de los niños que viven en una familia de homosexuales. Indica que "excluir a estas últimas del universo de potenciales adoptantes implica una limitación del derecho de los niños a tener una familia y no ser separados de ella, que afecta injustificada, irrazonable y desproporcionadamente su interés superior (CP art.44)".

2. De acuerdo a la Constitución, los tratados internacionales sobre derechos humanos, la jurisprudencia internacional y la jurisprudencia constitucional "la orientación sexual de una persona, o su sexo, no son por sí mismos indicadores de falta de idoneidad moral, física o mental para adoptar; de modo que impedir que un niño tenga una familia, fundándose para ello únicamente en la orientación sexual o el sexo de una persona o de una pareja, representa una restricción inaceptable de los derechos del niño, y es entonces además contrario a su interés superior, protegido por la Constitución y los instrumentos que se integran a ella". (Corte Constitucional colombiana, 2015).

3. Nuestra Constitución indica que desde el punto de vista del interés superior del menor no debe existir en la ley diferencia frente al sexo de las parejas ni de la orientación sexual de quienes la conforman.

4. La Corte verificó y reafirmó que es competente y legítima para resolver este caso en virtud del mandato del artículo 241 de la Constitución, además porque se trata de proteger derechos de población vulnerable como son los niños en estado de adoptabilidad frente a la interpretación de la ley que no es conforme con el interés superior del menor. Asimismo, "aclaró que cualquier proceso de adopción debe estar siempre dirigido a garantizar el interés superior del menor y el restablecimiento de sus derechos, y por tanto en todo caso será deber del Estado verificar, conforme a la Constitución y en los términos de esta sentencia, si se cumplen los demás requisitos establecidos en el ordenamiento jurídico".

Aunque en esta sentencia se trata el tema fundamental sobre el cual debe versar la adopción homoparental, cierto es que el interés superior del menor debe ser tenido en cuenta en todos los casos, no solo en aquellos de adopción por parte de parejas homosexuales; parece que la Corte condiciona a través de sus argumentos, que solo en aquellos casos en los que una pareja homosexual pretende adoptar a un menor, debe aplicarse esta regla, aunque también deba ser tenida en cuenta en los casos de adopción de parejas heterosexuales o de personas individuales. El punto de partida para analizar los casos de adopción que se presentan debe iniciar con la pregunta acerca de qué parejas son idóneas y aptas para adoptar a un menor, sin importar sus condiciones sexuales, religiosas, étnicas o de otra índole cultural; en este sentido, existirían parejas, tanto homosexuales, como heterosexuales que podrían no ser competentes para adoptar debido a factores condicionantes que pueden poner en riesgo la vida del infante.

La adopción no está, por sí misma, satisfaciendo un derecho constitucional o natural de las personas a adoptar, sino que está satisfaciendo tanto el derecho del niño a crecer y desarrollarse en una familia, como el interés de la sociedad en que las futuras generaciones se desarrollen y sean educadas. (Universidad Austral, 2010). Es por ello, que no existe un derecho a adoptar constitucionalmente consagrado.

Como lo exponen algunos catedráticos, entre ellos Carlos Martínez Aguirre de Saldaz, la figura "está configurada como una institución de protección de menores necesitados de su integración definitiva en un entorno familiar que permita su desarrollo integral: ese es - hay que subrayar nuevamente- el interés prevalente, al que deben 
atender tanto la Administración como el Juez" (Martínez Aguirre de Saldaz, 2007). Deben ser precisamente los jueces o autoridades administrativas quienes determinen en cada caso concreto si las circunstancias en las que el menor va a crecer al ser adoptado le permitirán tener una vida digna al lado de una familia.

Es por este motivo que la decisión de adoptar un menor implica la responsabilidad de afrontar en muchas ocasiones las tradiciones y condicionamientos sociales e institucionales. Con todo, es necesario que los debates actuales que versan sobre la adopción homoparental profundicen el reconocimiento de los derechos de los homosexuales, e incorporen los cambios estructurales de la familia contemporánea, además de identificar los cambios recientes en las normas legales, o en las prácticas de los tribunales, en asuntos que están relacionados con la adopción. (Nusdeo de Oliveira \& De Salles, 2006).

\section{A modo de reflexión: la armonización del principio del interés superior del niño, la necesidad de salvaguardar los derechos de las personas lesbianas, gay, bisexuales e intersexuales, y el principio de igualdad como fundamento de la adopción homoparental en Colombia.}

Frente a los cinco países objeto de estudio, se concluye inicialmente que las estructuras del Poder Judicial son análogas en cuanto a su forma de organización y respecto a los operadores jurídicos que emiten las decisiones (en este caso, referentes a la adopción de menores por parte de parejas homosexuales).

Comparten además otras características similares como la base en la supremacía de la Constitución, la prohibición de discriminación y la dignidad humana. De acuerdo con Rodrigo Uprimmy, la presencia de estos elementos permite establecer que gran parte de los países latinoamericanos integran entre sus características comunes la conceptualización de los principios ideológicos en la Constitución, denotado este fenómeno como "Constitucionalismo de la diversidad". (Uprimmy, 2011) Se reconocen además (al menos dentro del discurso jurídico introducido en sus leyes y fallos) como Estados que identifican la pluralidad de sus ciudadanos. Al respecto, podemos entonces concluir que México, Argentina y Uruguay han dado un paso mayor en el reconocimiento de la adopción homoparental, a partir de leyes que suprimen la vaguedad de los textos legislativos; Brasil por el contrario se asemeja más a lo que sucede en nuestro país, donde a través de fallos jurisprudenciales se ha regulado la adopción, siendo algunos de ellos contradictorios y evadiendo incluso introducir razones de fondo que versen sobre algo más que la prohibición de discriminación por la condición de homosexual de sus accionantes.

Las decisiones que versan sobre esta temática, sin embargo, han sido amparadas teniendo en cuenta generalmente, la prohibición de discriminación por la orientación sexual. Poco o nada se ha dicho respecto a los derechos de los menores a hacer parte de una familia, sea esta homosexual o heterosexual, lo cual ha delimitado el debate a la perspectiva de las parejas y las personas homosexuales individualmente consideradas, dejando de lado un aspecto bastante importante. La verdadera pregunta que existe puede resumirse en los siguientes términos: ¿si se les denegara la adopción a parejas homosexuales en virtud de su orientación sexual, se estaría respetando el interés superior del niño?

Al ser este el principio que regula y guía la adopción, es menester delimitar su significado. El interés superior del niño es un vocablo contenido a lo largo de la Convención sobre los Derechos del Niño donde refiere, por ejemplo, en su artículo 3, inciso 1, que 
“... En todas las medidas concernientes a los niños que tomen las instituciones públicas o privadas de bienestar social, los tribunales, las autoridades administrativas o los órganos legislativos, una consideración primordial a que se atenderá será el interés superior del niño..." (Organización de las Naciones Unidas, 2013). Precisamente, es a la luz de este principio básico en materia de derechos de infancia y adolescencia, que debería ampliarse el abanico de formas de organización familiar; esta ampliación debe comprender a las parejas del mismo sexo, siguiendo los tradicionales argumentos que se han introducido.

Es esencialmente el principio del interés superior del menor el que justifica la aceptación de diversos modelos de familia, que se encarguen de brindar la crianza y cuidado necesario a millones de niños que día a día se encuentran a la deriva, toda vez que la adopción no recae sobre los padres adoptantes, sino especialmente sobre el menor adoptado; no existe derecho a adoptar expresamente consagrado, existe, si, el derecho de los menores a ser adoptados y convivir en un ambiente de respeto y tolerancia; de esta manera, el discurso jurídico sobre la adopción homoparental debe versar, inicialmente, sobre la posibilidad que los menores puedan hacer parte de una familia y desarrollarse plenamente en un entorno de hogar.

Por este motivo, se evidencia una redefinición en el concepto tradicional de familia, en razón de la necesidad de ampliarlo en el escenario moderno; este es un argumento recurrente en todas las producciones jurídicas y dogmáticas analizadas en el presente escrito, lo que denota una clara preocupación por parte de la literatura científica en presentar posiciones menos herméticas y más congruentes con las transformaciones de la sociedad y los contextos actuales de la parentalidad y la crianza de menores.

De esta manera, en el caso colombiano toda disposición que estableciera un trato diferente entre las parejas homosexuales y heterosexuales, era considerado conforme a la constitución y no debía ser sometido a un estricto test de constitucionalidad. En esta primera etapa jurisprudencial, la Corte no reconoció la existencia jurídica de las parejas del mismo sexo como familia.

Identificamos que existió durante muchos años un limbo jurídico al respecto. Posteriormente, la Corte comienza a dar alcances distintos a los conceptos que el artículo 42 de la Constitución presenta respecto a la fundación nuclear de la familia, dando el paso a que las parejas homosexuales se asimilen completamente, en lo que les pueda corresponder, a las uniones heterosexuales que consiguen fundar un vínculo familiar por el compromiso responsable y ante las dinámicas de existencia del amor que se manifiestan, incluyendo la apertura a una comunidad doméstica de crianza y solidaridad. La Corte asume un nuevo protagonismo bajo el supuesto de que, siendo guardiana de la Constitución, y en su deber de interpretarla, muestra cómo debe haber una especial protección por parte del Estado a la decisión soberana y responsable de conformar una familia por parte de las parejas homosexuales. (Machado Jiménez, 2014).

Así, la sentencia SU-617 de 2014 supone un hito en el reconocimiento de esta figura en el país; los argumentos introducidos, por el contrario, generan ciertas dudas sobre la manera en la que Corte decide sus fallos, amparando los derechos de los accionantes, pero, como en muchas otras ocasiones, eludiendo introducir razones jurídicas que versen sobre la protección de los derechos objeto de demanda, y no sobre situaciones fácticas de los accionantes. 
De este modo, a falta de protección legislativa que se le brinde a la comunidad LGT$\mathrm{BI}$ ha sido tarea de la Corte reconocer muchos de los derechos por medio múltiples de fallos, y en ocasiones hace exhortaciones al Congreso de la República para que legisle sobre los debates en cuestión. A lo largo de este proceso, como se evidencia en el recorrido realizado en la jurisprudencia, en sus diversos pronunciamientos, la Corte hizo el reconocimiento de muchos derechos fundamentales, pero a su vez se negaron algunos, que fueron aceptados posteriormente, de la misma manera, en sus decisiones se evidencia que no se hizo pronunciamiento alguno de los derechos solicitados.

Aunque estos reconocimientos son fundamentales y válidos en nuestro ordenamiento jurídico para superar la desigualdad que existía entre las parejas homosexuales y heterosexuales en cuanto a la adopción de hijos, es preciso que el órgano legislativo se ponga al frente de la situación y legisle todo lo referente a adopción y matrimonio incluyendo a las parejas del mismo sexo, de la misma manera, es su obligación hacer las modificaciones a todas las normas vigentes sobre esta institución y así terminar con cualquier tipo de impedimento que pueda presentarse en la aplicación de la sentencia en la que la corporación permite a estas parejas adoptar.

La Corte Constitucional ha sido aún tímida en sus decisiones, concediendo el amparo de los derechos de las parejas homosexuales, pero guardando silencio sobre otros factores realmente importantes en el debate, como son el concepto de familia en la sociedad colombiana, el interés superior del menor y la posibilidad de ser parte de una familia, incluso los nuevos factores reales de poder que imperan en nuestra sociedad; parece que sus argumentos han partido de la base de los derechos de las personas homosexuales individualmente considerados y no de la posibilidad que también tienen los menores formar una familia, incluso cuando ya las investigaciones científicas demuestran que no existen riesgos mayores a los que podría enfrentarse un menor si es adoptado por una pareja homosexual a los que existen si esa familia es heterosexual.

Por ello, el debate sobre la adopción homoparental en el continente, y especialmente en Colombia está lejos de terminar. La familia nuclear como tradición occidental está tornándose cada vez más una minoría. Sin embargo, la idea de esta clase de familias formadas a partir del matrimonio heterosexual y monogámico aún figura como norma instalada en el imaginario colectivo, siendo las diversas configuraciones familiares generalmente clasificadas a partir de esta referencia. Las entidades familiares reconocidas dentro de los diversos ordenamientos jurídicos del continente son meramente enunciativas, que no permiten excluir cualquier otra relación que figure dentro del ámbito de afectividad y efectividad. La jurisprudencia y doctrina nacional e internacional coinciden al afirmar que no puede obviarse que son los intereses de los adoptados, y no los de los adoptantes, los que deben guiar el espíritu de toda ley de adopción. Es precisamente esta la razón por la cual la Convención de los Derechos del Niño señala que "Los Estados Partes que reconocen o permiten el sistema de adopción cuidarán de que el interés superior del niño sea la consideración primordial". Muchos otros asuntos quedan aún sobre el tintero, la discusión está lejos de terminar, pero es lo suficientemente valioso enfrentar a través del discurso jurídico sobre la protección de los derechos humanos y el bienestar de todos los menores del país y el continente, un tema que requiere ser legislado (aquí, y ahora).

\section{Referencias}

Acción de Inconstitucionalidad 2/2010 (Tribunal Pleno de la Suprema Corte de Justicia de la Nación 16 de agosto de 2010). Versión digital disponible en: https:// 
www.sitios.scjn.gob.mx/codhap/sites/default/files/engrosepdf sentenciarelevante/MATRIMONIO\%20MISMO\%20SEX0\%20AI\%202-2010 0.pdf.

Amparo en revisión 581/2012 (Primera Sala de la Suprema Corte de Justicia de la Nación 05 de diciembre de 2012).

Cifuentes, R. (2011). Diseño de proyectos de investigación cualitativa. Buenos Aires: Noveduc. Versión digital disponible en: file:///C:/Users/cmira/Downloads/Dialnet-DisenoDeProyectosDelnvestigacionCualitativa-4929358.pdf.

Cillero, M. (1994). Evolución histórica de la consideración jurídica de la infancia y adolescencia en Uruguay. Infancia en Riesgo Social y Políticas Sociales en Uruguay. Instituto Interamericano del Niño, p. 75-138.

Clavero Lerena, M. (2014). Adopción Homoparental: un estudio sobre la construcción de deseo de hijo en parejas gay. Montevideo, Uruguay.

Clérico, L. (2013). El caso Atala de la Corte IDH: posibilidades y perspectivas. . Biblioteca Jurídica Virtual del Instituto de Investigaciones Jurídicas de la UNAM, 81-101.

Comisión de de Derechos Humanos del Estado de Campeche, Acción de Inconstitucionalidad 8/2014 (Magistrada Ponente Margarita Beatriz Luna Ramos 2014).

Congreso Constitucional del Estado de Colima, Decreto 103 (11 de junio de 2016).

Corte Constitucional colombiana, Sentencia SU-617/2014 (Magistrado Ponente DR. Luis Guillermo Guerrero Pérez 28 de agosto de 2014).

Corte Constitucional colombiana, Sentencia T 290/95 (Magistrado Ponente Dr. Carlos Gaviria Diaz 5 de julio de 1995).

Corte Constitucional colombiana, Sentencia C 098/1996 (Magistrado Ponente Dr. Eduardo Cifuentes Muñoz 7 de marzo de 1996).

Corte Constitucional colombiana, Sentencia C 802/09 (Magistrado Ponente DR. Gabriel Eduardo Mendoza Martelo 10 de noviembre de 2009).

Corte Constitucional colombiana, Sentencia C 577/11 (Magistrado Ponente DR. Gabriel Eduardo Mendoza Martelo 26 de julio de 2011).

Corte Constitucional colombiana, Sentencia T-276/12 (Magistrado Ponente DR. Jose Ignacio Pretelt Chaljub 11 de abril de 2012).

Corte Constitucional colombiana, Sentencia C-683/15 (Magistrado Ponente DR. Jorge Iván Palacio Palacio 4 de noviembre de 2015).

De salles, C., \& De Oliveira Nusdeo, A. (2009). Adopción por homosexuales: el discurso jurídico. . SELA. Seminario en Latinoamérica de Teoría Constitucional y Política.

Federación Española de Sociedades de Sexología. (2005). Comunicado. Postura Oficial de la Federación Española de Sociedades de Sexología (FESS) Sobre el matrimonio y la adopción por parejas homisexuales. 45-50. 
Gómez Mazo, D., \& Velázquez Ocampo, O. P. (2012). La adopción de niños por parte de personas con orientaciones sexuales minoritarias: un análisis desde el interés superior del niño y la perspectiva del adoptante. Universidad EAFIT, 1-111.

Gonçalves Paraviso, I. (2012). Adoção por homossexuais. Curso de Pós-graduação em Direito Civil e Processo Civil da Fundação Aprender - Varginha.

Juzgado Civil, Comercial y Minas Na10 de Mendoza, Adopción y Homoparentalidad (20 de octubre de 1998).

Kochhann Scheeren, C., \& Hahn, N. B. (2016). ADOÇÃO CONJUNTA POR CASAIS HOMOSSEXUAIS NO BRASIL. Anais do Congresso Estadual de Teologia, 1-13.

Machado Jiménez, J. (2014). La transformación del concepto constitucional de familia. Alcances de una problemática teórica. . Díkaion, 93-133.

Martínez Aguirre de Saldaz, C. (2007). La adopción conjunta por matrimonios homosexuales: el efecto indirecto (pero querido) de una reforma matrimonial. Revista de Derecho Privado. Editoriales de Derecho Reunido. EDERSA, 3-32.

Martínez Rey, F. (2014). Caso de la Corte Interamericana de Derechos Humanos "Atala Riffo y Niñas contra Chile" (24 de febrero de 2012). Cuestiones Constitucionales. Revista mexicana de derecho constitucional, 237-249.

Nofal, L. (2010). Adopción homparental: derechos LGT a la adopción. Departamento de investigaciones de la Universidad de Belgrano.

Nusdeo de Oliveira, A., \& De Salles, C. (2006). Adopción por homosexuales: el discurso jurídico. Revista de Direito Universidade de São Paulo, 22-34.

Ordóñez Daza, S., \& Valencia Valencia, M. C. (2012). Adopción por parejas homosexuales: realidad social hacia el reconocimiento judicial. Universidad ICESI.

Organización de las Naciones Unidas. (2013). Comité de los Derechos del Niño. Observación General Nª 14 (2013) sobre el derecho del niño a que su interes superior sea una condición primordial.

Pizzorusso, A. (1987). Curso de derecho comparado. Barcelona: Editorial Ariel.

Radl, A. (2000). La dimensión cultura, base para el desarrollo de América Latina y el Caribe: desde la solidaridad hasta la integración. Banco Interamericano de Desarollo. Departamento de Integración y Programas Regionales, 17-28. Versión digital disponible en: https://publications.iadb.org/handle/11319/2759.

Silva Cecílio, M., Scorsolini-Comin, F., \& Antônio dos Santos, M. (2013). Produção científica sobre adoção por casais homossexuais no contexto brasileiro. Estudos de Psicologia, 503-516.

Universidad Austral. (2010). Matrimonio homosexual y adopción de parejas del mismo sexo. . Informe de estudios científicos y jurídicos y experiencia en otros países, $1-176$. 
Uprimmy, R. (2011). Las transformaciones constitucionales recientes en América Latina: en G.C.R. El derecho en América Latina: un mapa para el pensamiento jurídico del siglo XXI. Buenos Aires: Siglo Veintiuno Editores S.A. 